\title{
Análise de colonização bacteriana em copos umidificadores utilizados na oxigenoterapia em pacientes internados em um Hospital Universitário
}

Analysis of bacterial colonization in humidifying cups used in oxygen therapy in patients admitted to a University Hospital

Análisis de colonización bacteriana en copas humidificadoras utilizadas en oxigenoterapia en pacientes ingresados en un Hospital Universitario

Recebido: 04/03/2021 | Revisado: 11/03/2021 | Aceito: 15/03/2021 | Publicado: 21/03/2021

Carine Freitas e Silva

ORCID: https://orcid.org/0000-0002-3957-2052

Faculdade São Francisco de Juazeiro, Brasil

E-mail: ccarine_f@hotmail.com

Renivaldo Batista Dias

ORCID: https://orcid.org/0000-0003-0151-1059

Faculdade São Francisco de Juazeiro, Brasil

E-mail: renivaldodias@outlook.com

Marcela Ferreira Lapenda Figuerôa

ORCID: https://orcid.org/0000-0001-9168-5751

Universidade Federal do Vale do São Francisco, Brasil

E-mail: marcela_lapenda@hotmail.com

Fabricio Olinda de Souza Mesquita

ORCID: https://orcid.org/0000-0001-7514-2757

Universidade Federal do Vale do São Francisco, Brasil E-mail: fabricioolinda@hotmail.com

Carine Rosa Naue

ORCID: https://orcid.org/0000-0003-4215-3606 Universidade Federal do Vale do São Francisco, Brasil E-mail: crnaue@yahoo.com.br

\begin{abstract}
Resumo
Objetivo: Avaliar a segurança microbiológica da água nos copos umidificadores de pacientes em uso de oxigenoterapia e internados num Hospital Universitário do Vale do Submédio do São Francisco. Métodos: Trata-se de um estudo clínico, longitudinal, observacional envolvendo análise microbiológica da água dos umidificadores utilizados em oxigenoterapia. As amostras foram coletadas diariamente, durante um período de seis meses e analisadas pelo Laboratório de Análises Clínicas do Hospital Universitário. Para análise microbiológica, o material foi incubado a $37^{\circ} \mathrm{C}$ por 48 horas em tubos contendo $5 \mathrm{~mL}$ de Brain-Heart Infusion (BHI), depois semeado em Ágar Sangue. Foram consideradas contaminadas as amostras que apresentaram crescimento bacteriano. Para identificação das espécies bacterianas e o antibiograma, utilizou-se o sistema BD Phoenix TM 100. Resultados: Foram considerados elegíveis 52 pacientes, totalizando 279 amostras no período do estudo, destas, $20(7,16 \%)$ apresentaram contaminação bacteriana. Os patógenos mais incidentes foram: A. baumannii, E. cloacae, K. pneumoniae, S. epidermidis. Conclusão: Os dados obtidos permitem a adoção de estratégias mais seguras na utilização dos umidificadores da oxigenoterapia. Além disso, o conhecimento do perfil de resistência das bactérias, permite mais eficácia da terapia medicamentosa, prevenindo falhas terapêuticas.
\end{abstract}

Palavras-chave: Oxigenoterapia; Umidificadores; Bactéria.

\begin{abstract}
Objectives: To evaluate the microbiological safety of water in the humidifying cups of patients using oxygen therapy and admitted to a University Hospital in the Vale do Submédio do São Francisco. Methods: This is a clinical, longitudinal, observational study involving microbiological analysis of water from humidifiers used in oxygen therapy. The data were collected daily, during a period of six months and analyzed by the Clinical Analysis Laboratory of the University Hospital. For microbiological analysis, the material was incubated at $37^{\circ} \mathrm{C}$ for 48 hours in tubes containing $5 \mathrm{~mL}$ of Brain-Heart Infusion (BHI), then seeded on Blood Agar. They were considered contaminated as obtaining that bacterial growth. To identify bacterial species and the antibiogram, the BD Phoenix ${ }^{\mathrm{TM}} 100$ system was used. Results: 52 patients were considered, totaling 279 during the study period, these, 20 (7.16\%) bacterial contamination. The most incident pathogens were: A. baumannii, E. cloacae, K. pneumoniae, S. epidermidis. Conclusion: The data accept the
\end{abstract}


adoption of safer rules in the use of oxygen therapy humidifiers. In addition, knowledge of the resistance profile of bacteria allows more effective drug therapy, preventing therapeutic failures.

Keywords: Oxygen inhalation therapy, Humidifiers, Bacteria.

\section{Resumen}

Objetivos: Evaluar la seguridad microbiológica del agua en los vasos humidificadores de pacientes en tratamiento con oxigenoterapia e ingresados en un Hospital Universitario en el Vale do Submédio do São Francisco. Métodos: Este es un estudio clínico, longitudinal y observacional que involucra el análisis microbiológico del agua de los humidificadores utilizados en la oxigenoterapia. Los datos fueron recolectados diariamente, durante un período de seis meses y analizados por el Laboratorio de Análisis Clínicos del Hospital Universitario. Para el análisis microbiológico, el material se incubó a $37^{\circ} \mathrm{C}$ durante 48 horas en tubos que contenían $5 \mathrm{ml}$ de infusión cerebro-corazón (BHI), luego se sembró en agar sangre. Se consideraron contaminados por obtener ese crecimiento bacteriano. Para la identificación de especies bacterianas y el antibiograma se utilizó el sistema BD Phoenix TM 100. Resultados: Se consideraron 52 pacientes, totalizando 279 durante el período de estudio, estos $20(7,16 \%)$ contaminación bacteriana. Los patógenos más incidentes fueron: A. baumannii, E. cloacae, K. pneumoniae, S. epidermidis. Conclusión: Los datos aceptan la adopción de reglas más seguras en el uso de humidificadores de oxigenoterapia. Además, el conocimiento del perfil de resistencia de las bacterias permite una farmacoterapia más eficaz, evitando fracasos terapéuticos.

Palabras clave: Terapia por inhalación de oxígeno, Humidificadores, Bacterias.

\section{Introdução}

A oxigenoterapia consiste em um recurso terapêutico realizado por meio do fornecimento suplementar de oxigênio, ao paciente, em condições superiores a disponível no ar ambiente. A sua prescrição é realizada de acordo com as condições clínicas apresentadas pelo paciente, podendo ser administrada através de cateter nasal, cânula nasal, máscara facial ou máscara de Venturi, até que os valores de oxigênio arterial sejam restabelecidos (Spoletini et al., 2018).

Apesar de eficaz na correção de episódios de insuficiência respiratória, complicações comuns são evidenciadas durante a adoção da terapia por oxigênio, dentre elas, lista-se o ressecamento das mucosas nasal e oral causados pela secura do oxigênio ofertado, perda da função mucociliar, desidratação das mucosas provocando irritabilidade, inflamação e sangramento resultante da entrega do oxigênio frio e seco (Pires, 2018). A umidificação do oxigênio tem sido considerada uma alternativa eficaz para reduzir os problemas frequentes causados pela sequidão da oxigenoterapia permitindo melhora da ação do epitélio mucociliar e o conforto respiratório do paciente através de sistemas de alto ou baixo fluxo. No entanto, a umidificação utilizada constitui-se como um potencial meio de colonização por bactérias e fungos comumente associados em infecções nosocomiais, sobretudo nas infeções do trato respiratório (Dres \& Demoule, 2017). A duração do tempo de utilização da água do copo umidificador dependerá da necessidade de fluxo de oxigênio ofertado e da modalidade terapêtica empregada, contudo, ao passo que esse tempo de utilização é prologado, amplia-se a possibilidade de a água do copo umidificador contaminar, gerando dúvidas sobre a segurança da aplicabilidade da terapêutica por longos períodos (de la Fuente-Sancho et al., 2019). Aliado ao problema, estão comumente associados a este tipo de infeção, patógenos desencadeadores de pneumonias bacterianas. Esses eventos são motivados em sua grande maioria por bacilos gram negativos, com maior ocorrência de infecção por Pseudomonas aeruginosa, Klebsiella pneumoniae e Acinetobacter baumannii. Essas espécies bacterianas são habitualmente comuns em ambientes hospitalares associadas as infecções respiratórias graves, como a Pneumonia Associada a Ventilação Mecânica (PAV), resultante de grande morbidade e mortalidade (Behnia et al., 2014; Mallick et al., 2015). Estas cepas possuem grande resistência farmacológica em consequência dos antibióticos empiricamente empregados em seu tratamento. A resistência bacteriana é compreendida como um problema de saúde global a ser sanado em decorrências do impacto nos custos hospitalares por aumento do período de internação e insumos terapêuticos, além da piora do prognóstico clínico dos pacientes. O conhecimento da incidência e do perfil dos patógenos relacionados as infecções multirresistentes permite o estabelecimento de práticas terapêuticas assertivas, influindo na redução da suscetibilidade de microrganismos multirresistentes (Tabak et al., 2020).

As infecções do trato respiratório evidenciam-se entre as principais Infecções Relacionadas a Assistência à Saúde (IRAS) que, quando associadas as características clínicas dos pacientes, elevam os custos de tratamento, o período de internação 
e piora no desfecho dos assistidos. A partir do exposto, a presente pesquisa tem como objetivo avaliar o perfil bacteriológico da água de umidificadores usados na oxigenoterapia em pacientes internados em um hospital Universitário do Vale do Submédio do São Francisco.

\section{Metodologia}

No presente estudo foi utilizada metodologia de natureza qualitativa. Trata-se de um estudo clínico, longitudinal, observacional envolvendo a análise de amostras de água dos copos dos umidificadores utilizados em pacientes que fazem uso da oxigenoterapia internados em um Hospital Universitário do Vale do Submédio do São Francisco.

Foram adotados como critérios de inclusão o uso de umidificação na oxigenoterapia por tempo >24 horas, em pacientes inicialmente internados nos setores de UTI e Sala de Cuidados Intermediários (SCI). E para os critérios de exclusão, a adoção da oxigenoterapia sem água nos copos de umidificação e casos de paciente em Ventilação Mecânica Invasiva (VMI).

As coletas das amostras de água dos copos foram realizadas diariamente, entre os meses de outubro de 2019 e março de 2020, em seis setores: Clínica médica; Sala de Cuidados Intermediários; Unidade de Terapia Intensiva (UTI), Clínica Cirúrgica, Sala de Observação da Urgência e Emergência e Sala de Emergência. A primeira amostra coletada foi após 24 horas da instalação da oxigenoterapia com umidificador na Unidade de Terapia Intensiva ou na Sala de Cuidados Intensivos, sendo colhidas as próximas diariamente, até a suspensão do uso de oxigênio ou até a alta hospitalar.

Para cada amostra analisada foram coletados $3 \mathrm{~mL}$ da água contida nos umidificadores, a coleta era realizada pelos discentes envolvidos na pesquisa, devidamente equipados com luvas durante o processo. A água era transferida dos umidificadores diretamente para tubos tipo Falcon estéreis, que eram identificados com nome do paciente; setor; número de prontuário; data e número da coleta, e em seguida encaminhadas até o Laboratório de Análises Clínicas, setor Microbiologia, do Hospital Universitário.

Para a análise microbiológica, $1 \mathrm{ml}$ do material colhido foi transferido para tubos contendo $5 \mathrm{~mL}$ de Brain-Heart Infusion (BHI) e incubada a $37^{\circ} \mathrm{C}$ por 48 horas. Após o período de incubação, as amostras foram semeadas em Ágar Sangue e Ágar Macconkey. Considerou-se contaminadas as amostras das águas que apresentaram crescimento bacteriano. Quando houve crescimento, realizou-se a identificação das espécies bacterianas, assim como o antibiograma, através do sistema automatizado BD Phoenix тм 100, da Becton Dickinson. Os dados obtidos foram digitados em arquivos no formato tabelas e gráficos no software Microsoft Office Excel 7 e realizada análise descritiva, onde foi calculada a média por pacientes.

\section{Resultados}

No período analisado, realizaram-se as coletas de 52 pacientes, diariamente, desde às primeiras $24 \mathrm{~h}$ de uso de oxigenoterapia com umidificação ao longo do período de permanência hospitalar e a amostra final foi constituída por 279 coletas, o que significa uma média de 5,36 amostras por paciente.

Das 279 amostras, 20 apresentaram colonização bacteriana, representando 7,16\% do total de amostras (Gráfico 1). 
Gráfico 1. Porcentagem de amostras positivas e negativas coletadas da água de umidificadores de oxigênio coletada em pacientes internados em um Hospital Universitário, no período de outubro de 2019 a março de 2020.

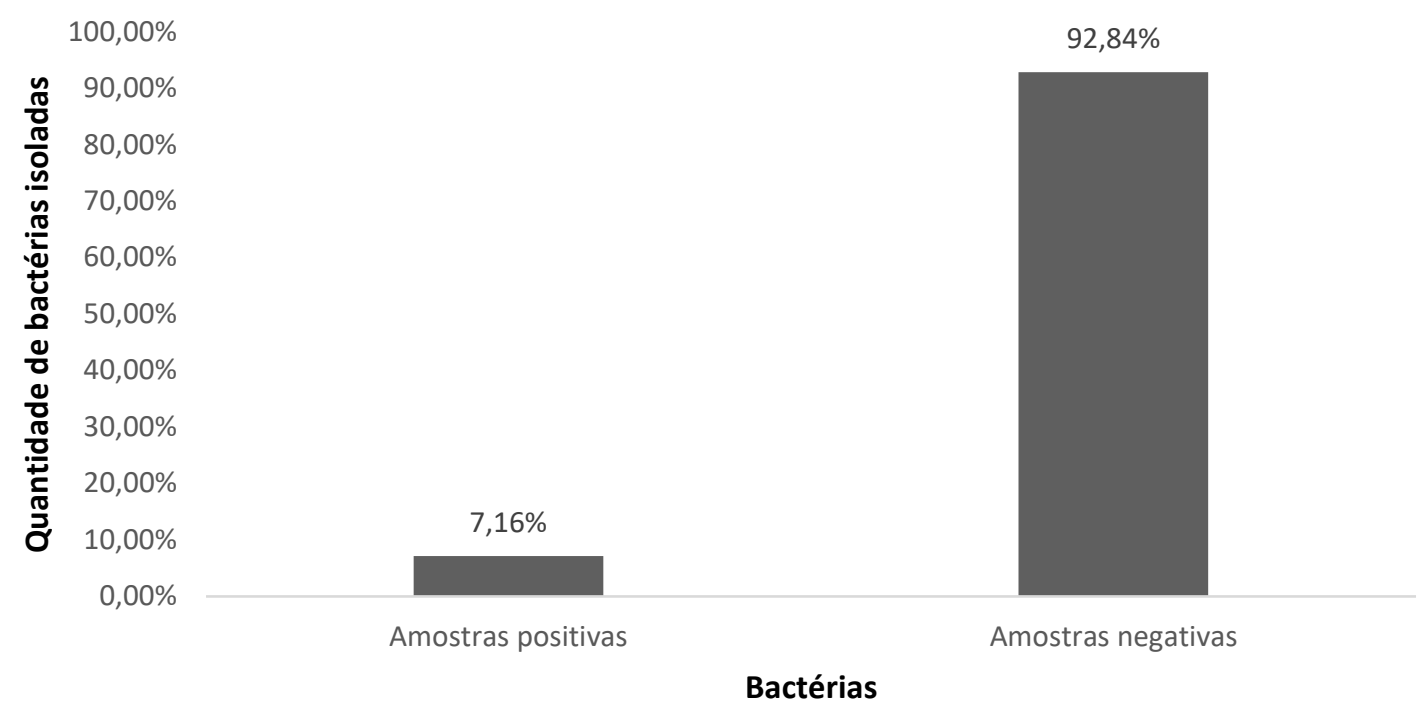

Fonte: Autores.

A coleta das amostras das águas dos umidificadores ocorreu em 6 setores. Observou-se que, entre estes, apenas 4 setores apresentaram amostras positivas: Clínica médica (9); Sala de Cuidados Intermediários (4); Unidade de Terapia Intensiva (4) e Clínica Cirúrgica (3) (Gráfico 2). À vista disso, foi constatado que não houve colonização bacteriana nas amostras coletadas na Sala de Observação da Urgência e Emergência e na Sala de Emergência.

Gráfico 2. Setores que apresentaram colonização bacteriana nos umidificadores de pacientes internados em um Hospital Universitário, no período de outubro de 2019 a março de 2020.

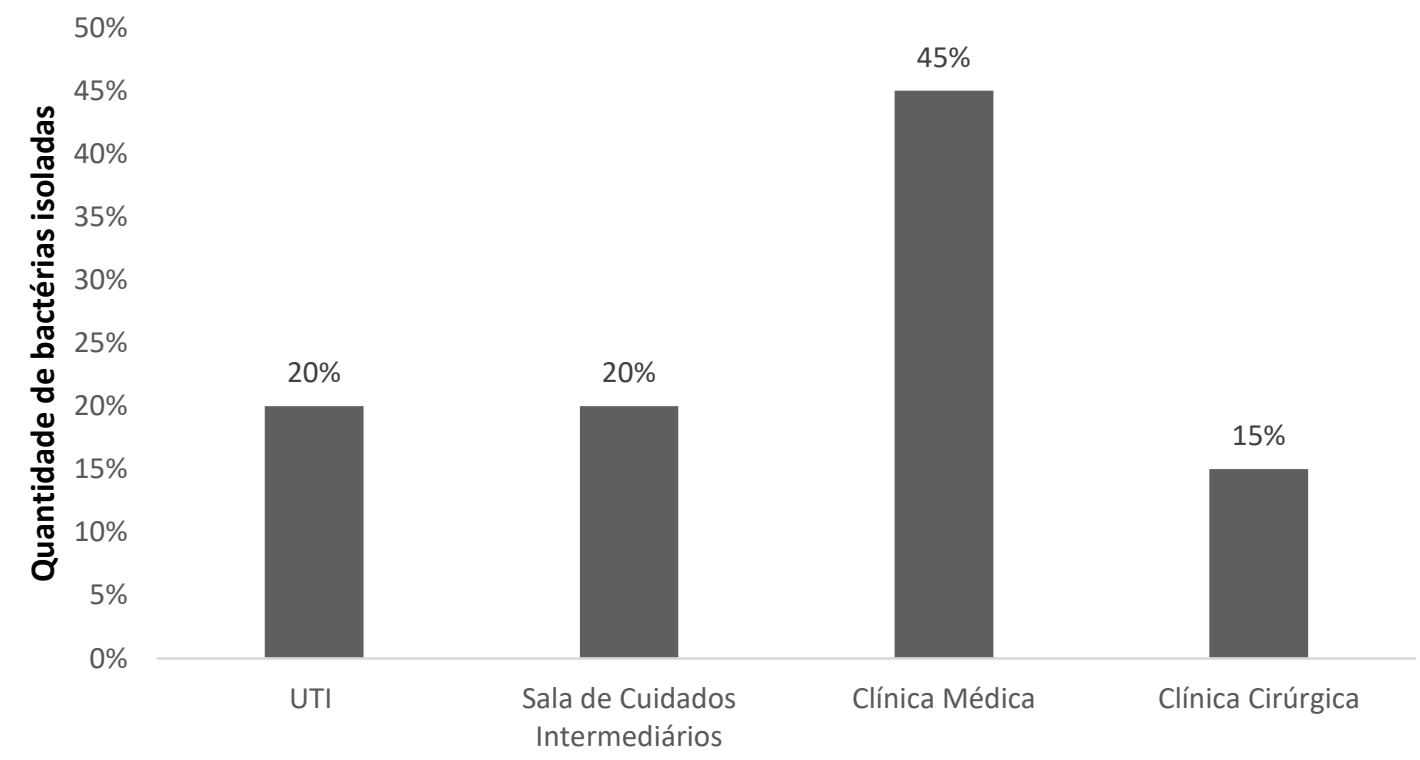

Bactérias

Fonte: Autores. 
Destas amostras coletadas, conforme o Gráfico 3, as espécies bacterianas, possíveis causadoras de infecções hospitalares, mais isoladas foram Acinetobacter baumannii (1,07\%) e Enterobacter cloacae (1,07\%). Houve, ainda, outras bactérias com menor incidência identificadas, no entanto, todas representavam valores abaixo de $1 \%$.

Gráfico 3. Ocorrência de bactérias isoladas da água de umidificadores de oxigênio coletada em pacientes internados no Hospital Universitário, no período de outubro de 2019 a março de 2020.

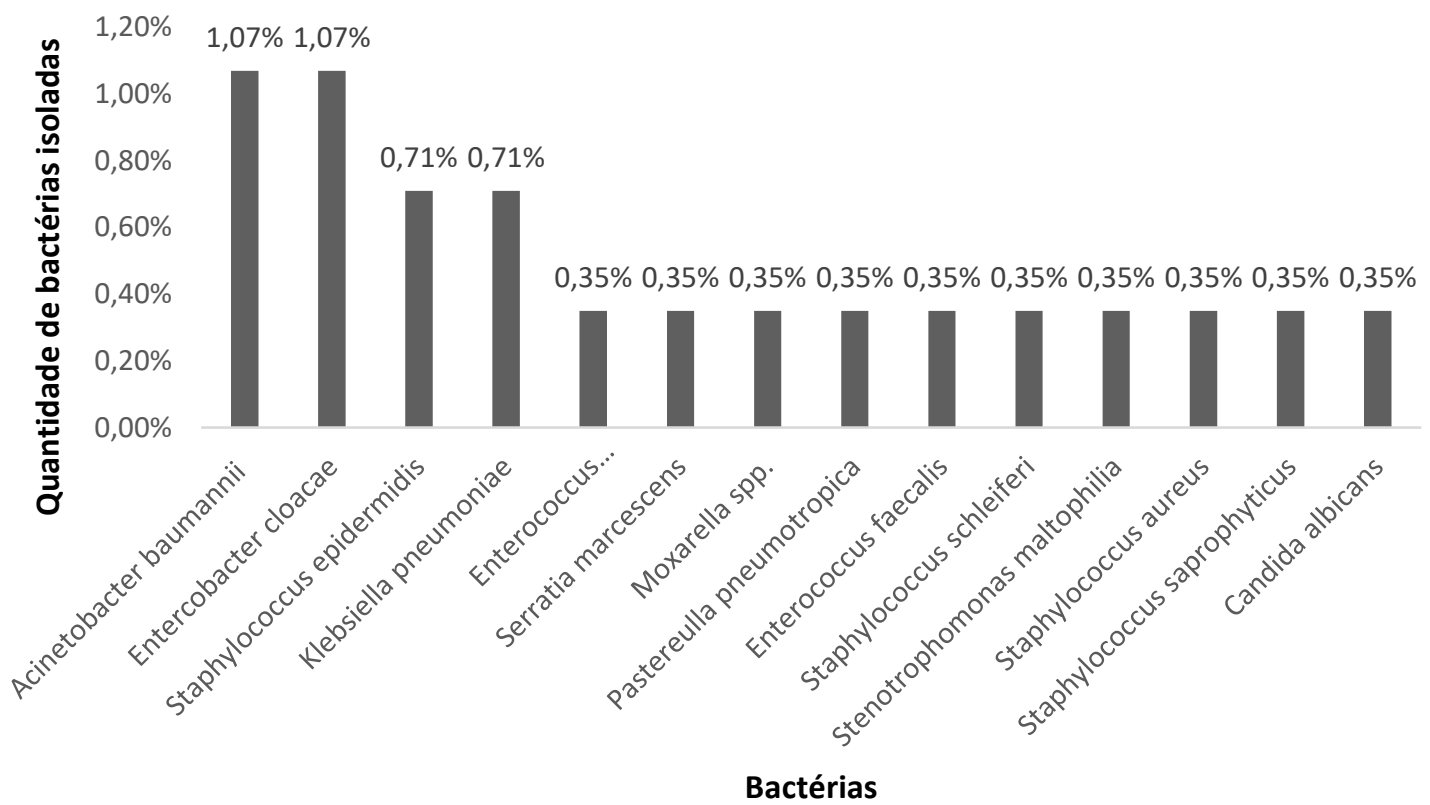

Fonte: Autores.

Pode-se observar, na Tabela 1, o perfil de resistência das bactérias mais isoladas na água dos umidificadores de oxigênio de pacientes internados no Hospital Universitário. 
Tabela 1: Perfil de resistência das bactérias mais isoladas na água de umidificadores de oxigênio de pacientes internados em um Hospital Universitário, no período de outubro de 2019 a março de 2020.

\begin{tabular}{|c|c|c|c|c|c|c|c|c|}
\hline \multirow[t]{3}{*}{ Antimicrobianos } & \multicolumn{8}{|c|}{ Espécies bacterianas } \\
\hline & \multicolumn{2}{|c|}{ A. baumannii } & \multicolumn{2}{|c|}{ E. cloacae } & \multicolumn{2}{|c|}{ K. pneumoniae } & \multicolumn{2}{|c|}{ S. epidermidis } \\
\hline & $\mathbf{n}$ & $\%$ & $\mathbf{n}$ & $\%$ & $\mathbf{n}$ & $\%$ & $\mathbf{n}$ & $\%$ \\
\hline Ampicilina & NT & NT & 3 & $100 \%$ & 2 & $100 \%$ & NT & NT \\
\hline Amicacina & 2 & $67 \%$ & 0 & $0 \%$ & 0 & $0 \%$ & NT & NT \\
\hline Amp+sub & 2 & $67 \%$ & 3 & $100 \%$ & 2 & $100 \%$ & NT & NT \\
\hline Cefepime & 2 & $67 \%$ & 2 & $67 \%$ & 2 & $100 \%$ & NT & NT \\
\hline Ceftazidina & 3 & $100 \%$ & NT & NT & NT & NT & NT & NT \\
\hline Cefazolina & NT & NT & 3 & $100 \%$ & NT & NT & NT & NT \\
\hline Cefoxitina & NT & NT & 3 & $100 \%$ & 2 & $100 \%$ & NT & NT \\
\hline Ceftriaxona & NT & NT & 0 & $0 \%$ & 2 & $100 \%$ & NT & NT \\
\hline Ciprofloxacino & 3 & $100 \%$ & 0 & $0 \%$ & 2 & $100 \%$ & NT & NT \\
\hline Clindamicina & NT & NT & NT & NT & NT & NT & 0 & $0 \%$ \\
\hline Daptomicina & NT & NT & NT & NT & NT & NT & 0 & $0 \%$ \\
\hline Eritromicina & NT & NT & NT & NT & NT & NT & 1 & $50 \%$ \\
\hline Ertapnem & NT & NT & 2 & $67 \%$ & 2 & $100 \%$ & NT & NT \\
\hline Gentamicina & 2 & $67 \%$ & 0 & $0 \%$ & 1 & $50 \%$ & NT & NT \\
\hline Imipenem & 2 & $67 \%$ & 2 & $67 \%$ & 1 & $50 \%$ & NT & NT \\
\hline Linezolide & NT & NT & NT & NT & NT & NT & 0 & $0 \%$ \\
\hline Levofloxacino & 3 & $100 \%$ & NT & NT & 2 & $100 \%$ & NT & NT \\
\hline Oxacilina & NT & NT & NT & NT & NT & NT & 0 & $0 \%$ \\
\hline Minociclina & NT & NT & NT & NT & NT & NT & 0 & $0 \%$ \\
\hline Meropenem & 2 & $67 \%$ & 2 & $67 \%$ & 2 & $100 \%$ & NT & NT \\
\hline Pipe+taz & 2 & $67 \%$ & 0 & $0 \%$ & 2 & $100 \%$ & NT & NT \\
\hline Rifampicina & NT & NT & NT & NT & NT & NT & 0 & $0 \%$ \\
\hline Smt+tmp & 0 & $0 \%$ & 0 & $0 \%$ & 2 & $100 \%$ & 1 & $50 \%$ \\
\hline Tigeciclina & NT & NT & 0 & $0 \%$ & 1 & $50 \%$ & NT & NT \\
\hline Vancomicina & NT & NT & NT & NT & NT & NT & 0 & $0 \%$ \\
\hline
\end{tabular}

Legenda: NT: não testado; n: número de isolados bacterianos; \%: percentual de resistência; pipe+tazo: piperacilina + tazobactam; smt+tmp: sulfametoxazol + trimetoprima; amp+sub: ampicilina + sulbactam; amox+clav: amoxicilina + clavulanato. Fonte: Autores.

Em relação ao perfil de resistência das principais bactérias identificadas, conforme observa-se na tabela, Acinetobacter baumannii foi $100 \%$ resistente a ceftazidina, ciprofloxacino e levofloxacino, $67 \%$ resistente a amicacina, ampicilina+sulbactam, cefepime, gentamicina, imipenem, meropenem, piperacilina+tazobactam, e 100\% sensível à sulfametoxazol+trimetoprima.

Ainda avaliando o perfil de resistência dos gram negativos, no presente estudo, observou-se $100 \%$ de resistência das cepas de E. cloacae para ampicilina; ampicilina+sulbactam; cefazolina e cefoxitina, e $67 \%$ para os antimicrobianos cefepime; ertapenem; imipenem e meropenem, e 100\% de sensibilidade a amicacina; ceftriaxona; ciprofloxacino; gentamicina; piperacilina+tazobactam; sulfametoxazol+trimetoprima e tigeciclina.

Os isolados de K. pneumoniae apresentaram $100 \%$ de resistência a ampicilina, ampicilina+sulbactam, cefepime, cefoxitina, ceftriaxona, ciprofloxacino, ertapenem, levofloxacino, meropenem, piperacilina+tazobactam e sulfametoxazol+trimetoprima, e 50\% de resistência a gentamicina; imipenem e tigeciclina. Observou-se, também, 100\% de sensibilidade a amicacina.

Quanto aos isolados de S. epidermidis pode-se observar $50 \%$ de resistência a eritromicina e sulfametoxazol+trimetoprima, bem como, $100 \%$ de sensibilidade a clindamicina, daptomicina, linezolide, oxacilina, minociclina, rifampicina e vancomicina. 


\section{Discussão}

A colonização bacteriana ocorreu na água de 20 umidificadores, que representam 7,16\% das 279 amostras coletadas no período do presente estudo. Um aspecto fundamental no que concerne estes resultados é a rotina de substituição destes umidificadores, portanto, vale ressaltar que para o presente estudo foram avaliados somente umidificadores reutilizáveis, conforme disponível na instituição de saúde onde realizou-se o estudo.

Em um estudo realizado no hospital de Minas Gerais (MG), cujo intuito foi avaliar a qualidade microbiológica da água utilizada na oxigenoterapia invasiva e não invasiva foi observado que $2(10 \%)$ dos 20 umidificadores fixos no painel beira-leito apresentaram contaminação bacteriana, especificamente de Pseudomonas aeruginosa, estes dados se aproximam do presente estudo na porcentagem de contaminação microbiana identificada. No entanto, a descrição dos métodos deste estudo não esclarece se a rotina adotada para manutenção da umidificação incluiu o uso de umidificadores reutilizáveis ou descartáveis (Seabra et al., 2012).

Em outro estudo, realizado no Hospital Universitário de Messina (Itália), onde foram analisados umidificadores reutilizáveis e descartáveis, as evidências de contaminação biológica em umidificadores de oxigênio reutilizáveis foram bastante consideráveis. Todos os setores onde foram avaliados umidificadores reutilizáveis apresentaram taxas de contaminação acima de 50\%, foram eles: enfermaria de Medicina Interna (82\%); enfermaria de Pneumologia (84\%); área médica (83\%); enfermaria de Cirurgia Geral (80\%); enfermaria de Cirurgia Torácica e Cardiovascular (74\%) e Unidade de Terapia Intensiva (40\%) (La Fauci et al., 2017). Estes valores divergem do presente estudo, onde mesmo na Clínica Médica, setor onde houve a maior taxa de contaminação, a taxa de contaminação foi apenas $9 \%$.

Quanto à segurança microbiológica desta técnica, uma metanálise realizada em 2017, onde foram identificados estudos de 1980-2016 e avaliada a eficácia da oxigenoterapia de baixo fluxo umidificada e não umidificada, constatou que o oxigênio não umidificado oferece mais benefícios por reduzir a probabilidade de contaminação bacteriana em umidificadores. No entanto, caracterizou a qualidade da maioria dos estudos como baixa e ressaltou a necessidade de ensaios clínicos randomizados em larga escala para avaliar a não umidificação da oxigenoterapia (Wen et al., 2017). Em 2019 foi conduzida outra metanálise sobre o tema, desta vez na Espanha. Para esta revisão, foram selecionados 12 estudos observacionais ou experimentais publicados entre 1990 e 2016. Em seus resultados também se observou que as evidências de contaminação estavam majoritariamente nos umidificadores reutilizáveis, enquanto a incidência nos umidificadores descartáveis foi irrelevante (de la Fuente-Sancho et al., 2019).

Os protocolos adotados no uso dos umidificadores são relevantes para os dados microbiológicos, pode-se observar que as instituições que adotaram umidificadores reutilizáveis apresentaram maior incidência bacteriana, no entanto destaca-se uma limitação nas metodologias dos estudos, que não apresentaram descrição minuciosa da periodicidade do reabastecimento ou troca dos frascos.

Em nosso estudo, os setores onde identificamos colonização bacteriana adotam rotinas diferentes para manutenção dos umidificadores, enquanto na Unidade de Terapia Intensiva e na Clínica Médica os frascos umidificadores são trocados a cada 24 horas, na Sala de Cuidados Intensivos e na Clínica Cirúrgica é realizado o reabastecimento à medida que o nível da água é reduzido, ou seja, os mesmos umidificadores permanecem com os pacientes durante toda a estadia nestes setores.

Devido à escassez de estudos que também objetivassem avaliar a segurança microbiológica desta técnica e principalmente de estudos realizados por profissionais de fisioterapia, este estudo limitou-se às poucas literaturas disponíveis. Não foram identificados artigos brasileiros publicados com este tipo de avaliação após 2012, do mesmo modo, não se identificou nestes artigos profissionais fisioterapeutas envolvidos na pesquisa, mesmo sendo a oxigenoterapia competência exclusiva destes profissionais. 
Quanto ao perfil bacteriano, no presente estudo, foi identificado que 57\% das bactérias identificadas foram gram negativas. Este dado se aproxima ao disposto no estudo supracitado onde foram observados $68 \%$ gram negativas entre as bactérias identificadas. Os resultados corroboram também em 5 espécies das bactérias que foram identificadas em ambos estudos, a saber: Serratia marcescens; Klebsiella pneumoniae; Acinetobacter baumannii/calcoaceticus complexo; Stenotrophomonas maltophilia; Staphylococcus aureus (La Fauci et al., 2017).

Apesar de comuns nas Infecções Relacionadas a Assistência à Saúde, a frequência dessas bactérias nos umidificadores de oxigênio analisados pode ser relacionada à capacidade de fácil contaminação, principalmente em ambientes favoráveis como na água dos frascos. Agravadas pela multirresistência bacteriana, infecções comuns evoluem para desfechos negativos devido à alta complexidade terapêutica, além disso, devido ao impacto no sistema imunológico dos pacientes alguns procedimentos interventivos que venham a ser necessários, como cirurgias, podem se tornar impraticáveis e inviabilizar o tratamento de patologias associadas (Dellalibera-Joviliano et al., 2020).

Considerando isto, apesar da pequena porcentagem de contaminação bacteriana das amostras das águas dos umidificadores, o perfil de resistência exige atenção.

A bactéria gram negativa A. baumannii, cuja ocorrência nas águas dos umidificadores foi significativa, possui alta patogenicidade e relaciona-se na causalidade de muitas das IRAS. Os resultados do presente estudo corroboram com os dados disponíveis em um estudo realizado em 2018 onde as cepas de A. baumanni também demonstraram altos percentuais de resistência a ceftazidima (99,7\%); ciprofloxacino (99,7\%); levofloxacino (100\%); amicacina (76,8\%); ampicilina+sulbactam (90\%); cefepime (99,7\%); gentamicina (51,9\%); imipenem (100\%); piperacilina+tazobactam (99,4\%) (Sousa, 2019).

Observa-se que os bacilos gram negativos identificados no presente estudo apresentaram elevada resistência às cefalosporinas, como também à ampicilina, quinolonas e aos carbapenêmicos. Similarmente, um estudo realizado em um Hospital Goiânia ao analisar o perfil de resistência bacteriana dos bacilos gram negativos frente a estes antimicrobianos identificou amostras com alta resistência às mesmas classes que identificamos (Mota et al., 2018). Além disso, em uma pesquisa realizada no mesmo hospital terciário do presente estudo, foram analisadas culturas coletadas em aspirados traqueais dos pacientes internados na UTI e descritos resultados semelhantes. Quanto às espécies bacterianas mais ocorrentes destacaram-se a Acinetobacter baumannii e Klebsiella pneumoniae. Em relação a resistência bacteriana foi possível observar para A. baumannii elevados níveis de resistência a ceftazidina, ciprofloxacino, levofloxacino, amicacina, ampicilina +sulbactam, cefepime, gentamicina, imipenem, meropenem e piperacilina+tazobactam, tais dados se assemelham aos nossos resultados quando comparadas as taxas de resistência às classes: cefalosporinas, quinolonas, penicilinas, aminoglicosídeos, carbapenems. Quanto à K. pneumoniae, também foram descritos resultados semelhantes aos nossos, observou-se elevados níveis de resistência às penicilinas, cefalosporinas, quinolonas e carbapenêmicos (Naue et al., 2019).

Esses achados, além de favorecer a especificidade no diagnóstico das infecções instaladas, se associados aos resultados obtidos no presente estudo, permitem ainda a adoção de medidas preventivas e/ou terapêuticas mais eficazes.

Diante desse perfil, a ocorrência de isolados com essas características é preocupante e resulta em grande impacto clínico, tendo em vista a escassez de terapias medicamentosas efetivas.

Dentro dessa realidade, cabe ressaltar que a limitação das estratégias medicamentosas relacionadas às infecções aumenta o tempo em internamento hospitalar, assim como as comorbidades associadas e a taxa de mortalidade, e assim, considerando o aumento da complexidade do paciente o tratamento torna-se mais oneroso tanto para as famílias e quanto para o sistema de saúde (Aquim et al., 2019).

Os pacientes críticos acometidos pelas infecções relacionadas à assistência à saúde (IRAS) são acometidos por complicações que influenciam significativamente em sua recuperação, quanto maior o tempo em internamento hospitalar maiores são as chances de que a imobilidade repercuta em alterações musculares, incluindo atrofia e fraqueza do músculo esquelético, 
diretamente relacionadas à prejuízos na funcionalidade que podem perdurar por até 5 anos após a alta hospitalar (Lone et al., 2016).

\section{Conclusão}

O presente estudo permite o conhecimento das bactérias mais incidentes nas amostras analisadas, bem como, do perfil de resistência das mesmas, além disso caracteriza a distribuição desses resultados nos diversos setores avaliados, ressaltando a relevância de um procedimento operacional padrão confiável para prevenção de possíveis infecções durante o uso de umidificadores, e também, destacando a importância da educação permanente para as medidas assépticas nos serviços de saúde. O conhecimento do perfil de resistência das bactérias identificadas no estudo permite, ainda, ao serviço de saúde estudado mais eficácia da terapia medicamentosa, prevenindo falhas terapêuticas e garantindo maiores chances de desfechos positivos para o paciente. Outrossim, vale ressaltar que pesquisas futuras são necessárias para ampliar a conhecimento do potencial infeccioso dessa técnica, e assim, de modo supervisionado fundamentar os melhores protocolos preventivos associados à essa ferramenta.

\section{Referências}

Aquim, E. E., Bernardo, W. M., Buzzini, R. F., de Azeredo, N. S. G., da Cunha, L. S., Damasceno, M. C. P., de Oliveira Deucher, R. A., Duarte, A. C. M., Librelato, J. T., Melo-Silva, C. A., Nemer, S. N., da Silva, S. D. F., \& Verona, C. (2019). Brazilian guidelines for early mobilization in intensive care unit. Revista Brasileira de Terapia Intensiva, 31(4), 434-443. https://doi.org/10.5935/0103-507X.20190084

Behnia, M., Logan, S. C., Fallen, L., \& Catalano, P. (2014). Nosocomial and ventilator-associated pneumonia in a community hospital intensive care unit: A retrospective review and analysis. BMC Research Notes, 7(1), 1-9. https://doi.org/10.1186/1756-0500-7-232

de la Fuente-Sancho, I., Romeu-Bordas, Ó., Fernández-Aedo, I., Vallejo De la Hoz, G., \& Ballesteros-Peña, S. (2019). Contaminación microbiológica en humidificadores de sistemas de oxigenoterapia de alto y bajo flujo: una revisión sistemática. Medicina Intensiva, 43(1), 18-25. https://doi.org/10.1016/j.medin.2017.11.003

Dellalibera-Joviliano, R., De Melo, S. A., \& Ceni, H. D. M. R. (2020). Alternativas terapêuticas e aplicação de bacteriófagos como estratégia no uso de antibióticos no tratamento de doenças bacterianas. Revista de Medicina, 99(1), 88-95. https://doi.org/10.11606/issn.1679-9836.v99i1p88-95

Dres, M., \& Demoule, A. (2017). What every intensivist should know about using high-flow nasal oxygen for critically ill patients. Revista Brasileira de Terapia Intensiva, 29(4), 399-403. https://doi.org/10.5935/0103-507X.20170060

La Fauci, V., Costa, G. B., Facciolà, A., Conti, A., Riso, R., \& Squeri, R. (2017). Humidifiers for oxygen therapy: What risk for reusable and disposable devices? Journal of Preventive Medicine and Hygiene, 58(2), E161-E165. https://doi.org/10.15167/2421-4248/jpmh2017.58.2.698

Lone, N. I., Gillies, M. A., Haddow, C., Dobbie, R., Rowan, K. M., Wild, S. H., Murray, G. D., \& Walsh, T. S. (2016). Five-year mortality and hospital costs associated with surviving intensive care. American Journal of Respiratory and Critical Care Medicine, 194(2), 198-208. https://doi.org/10.1164/rccm.201511$22340 \mathrm{OC}$

Mallick, U. K., Faruq, M. O., Ahsan, A. A., Fatema, K., Ahmed, F., Asaduzzaman, M., Islam, M., \& Sultana, A. (2015). Spectrum of Early Onset and Late Onset Ventilator Associated Pneumonia (VAP) in a Tertiary Care Hospital of Bangladesh: A Prospective Cohort Study. Bangladesh Critical Care Journal, 3(1), 913. https://doi.org/10.3329/bccj.v3i1.24095

Mota, F. S. da, Oliveira, H. A. de, \& Souto, R. C. F. (2018). Perfil e prevalência de resistência aos antimicrobianos de bactérias Gram-negativas isoladas de pacientes de uma unidade de terapia intensiva. Revista Brasileira de Análises Clínicas, 50(3), 270-277.

Naue, C. R., Ribeiro, T., Ribeiro, R., Batista, K., \& Aquino, S. (2019). Ocorrência e perfil bacteriano de culturas coletadas em pacientes internados na unidade de terapia intensiva em um hospital terciário. HU Revista, 45(2), 122-133. https://doi.org/10.34019/1982-8047.2019.v45.25933

Pires, P. (2018). Cânulas Nasais de Alto Fluxo: Uma Alternativa de Oxigenoterapia na Insuficiência Respiratória Aguda. Medicina Interna, 25(2), 123-133. https://doi.org/10.24950/rspmi/revisao/240/2/2018

Seabra, E. R., Botelho, F. F., Maria, E., Dazio, R., Silva, R. B., \& Chavasco, J. K. (2012). Avaliação da qualidade microbiológica da água utilizada nos umidificadores em oxigenoterapia Assessment of microbiological quality of water used in oxygenotherapy humidifiers. $147-155$.

Sousa, M. I. C. (2019). Prevalência de infecções por Acinetobacter baumannii multirresistente em um hospital e maternidade do Sistema Único de Saúde.

Spoletini, G., Mega, C., Pisani, L., Alotaibi, M., Khoja, A., Price, L. L., Blasi, F., Nava, S., \& Hill, N. (2018). High-flow nasal therapy vs standard oxygen during breaks off noninvasive ventilation for acute respiratory failure: A pilot randomized controlled trial. Journal of Critical Care, 48, $418-425$.

Tabak, Y. P., Sung, A., Ye, G., Vankeepuram, L., Gupta, V., \& McCann, E. (2020). Attributable burden in patients with carbapenem-nonsusceptible gramnegative respiratory infections. PLoS ONE, 15(2), 1-13. https://doi.org/10.1371/journal.pone.0229393

Wen, Z., Wang, W., Zhang, H., Wu, C., Ding, J., \& Shen, M. (2017). Is humidified better than non-humidified low-flow oxygen therapy? A systematic review and meta-analysis. Journal Of Advanced Nursing, 73(11), 2522-2533. 